\title{
Evolución y creación: revelación y razón
}

\section{(Evolution and Creation: Revelation and Reason)}

\section{SANTIAGO COLLADO GONZÁLEZ}

Facultad Eclesiástica de Filosofía

Universidad de Navarra

scollado@unav.es

Resumen. Es frecuente considerar que la fe en general, y la Iglesia católica en particular, han sido y son un obstáculo para el desarrollo de la ciencia. La hostilidad de la Iglesia a las teorías evolutivas es uno de los argumentos a los que se acuden para defender esta tesis. En este trabajo se estudian la verdad histórica de la oposición de la Iglesia al Darwinismo. Finalmente y de una manera breve se ofrecen algunas líneas que pueden orientar la comprensión de la compatibilidad y armonía de las teorías evolutivas con la doctrina teológica de la creación.

Palabras clave: creación; evolución; ciencia y fe.

Abstract. Faith in general and the Catholic Church in particular have often been considered, and they still are, as an obstacle to the development of science. The alleged hostility of the Church to evolutionary theories is one of the arguments given by proponents of this thesis. This paper studies the historical truth of the Church's opposition to Darwinism. Finally, it outlines a proposal that could help to understand the harmony and compatibility between the evolutionary theories and the theological doctrine of creation.

Keywords: creation; evolution; science and faith. 


\section{Introducción}

El nacimiento de la ciencia experimental, que tuvo lugar durante los siglos XVI y XVII, supuso una auténtica revolución en nuestro modo de pensar la Naturaleza. Aunque sus éxitos justificaron su rápida difusión, sin embargo, su aceptación no fue pacífica en todas las instancias de la sociedad. La aparición de la ciencia empírica introdujo un elemento perturbador en el debate ya existente sobre fe y razón.

Aunque en un primer momento, por la ayuda que podría prestar en la defensa racional de la fe, la nueva racionalidad científica fue acogida con júbilo y esperanza, pronto sin embargo, fue empleada por algunos para tratar de mostrar que la fe era innecesaria para explicar la realidad humana y la del mundo. Desde entonces el debate fe-razón fue siendo desplazado por el debate ciencia-fe (Agazzi 1983, 99-100). Una visión muy simplista de este debate, que se desarrolló sobre todo en el siglo XIX, presenta a ambas instancias en constante combate. Es cierto que se han producido fricciones desde el principio. Paradigmático fue el caso Galileo que, como muy bien ha puesto de manifiesto el profesor Artigas en su trilogía sobre Galileo, sirvió a la Iglesia Católica para iniciar un proceso de comprensión y profundización en las relaciones entre ciencia y fe, como caso particular de las relaciones entre fe y razón: un diálogo sobre el que la Iglesia ya tenía secular experiencia. No cabe duda de que este caso, que todavía despierta interés, tuvo que ver con la mesurada posición de la Iglesia en lo que se podría considerar el segundo gran enfrentamiento entre ciencia y fe, esta vez protagonizado por el darwinismo. En el caso Galileo se cometieron errores por los que Juan Pablo II abrió una comisión de investigación, analizada por Artigas en el libro "Galileo y el Vaticano", y por los que Juan Pablo II pidió perdón cuando la comisión concluyó sus trabajos.

El enfrentamiento del darwinismo con la religión ha tenido mayores proporciones. Pero en este caso ha sido desde el ámbito protestante donde se ha sentado a la ciencia en el banquillo ante el tribunal de la fe. El debate abierto en Estados Unidos en el inicio del siglo XX entre darwinismo y crea- 
cionismo es la expresión de este enfrentamiento en el que, inicialmente, la ciencia fue encontrada culpable.

Hay un modo de entender la fe que nace de la crisis escolástica previa al renacimiento, el nominalismo, que la aísla de la razón y la constituye en una instancia separada e irracional. Este fenómeno ha sido lúcidamente delatado por Benedicto XVI, entre otros lugares, en su discurso de Ratisbona. Cuando la fe no busca entender, como predicaron con su ejemplo los grandes maestros medievales ("fides quaerens intellectum" de S. Anselmo, por ejemplo), y se concibe como una especie de muro que la razón no tiene derecho, ni puede franquear, entonces es fácil que esa fe, constituida en instancia independiente de la racionalidad, se convierta en fundamentalismo. Es el tribunal de la razón el que acaba desacreditando al fundamentalismo, como ha ocurrido, por ejemplo, en el debate Creacionismo-Evolucionismo.

El querer entender la fe, por supuesto, no implica tener la pretensión de agotar la verdad revelada, sino abrir la razón a un ámbito más amplio que el que pone ante los ojos de nuestro entendimiento la desnuda experiencia empírica.

El fundamentalismo es una de las patologías que nacen de una deficiente articulación de la ciencia, la razón y la fe. Cuando la ciencia se erige en razón suprema, en juez de la verdad, entonces es la patología del cientificismo la que nos sobreviene. Esta constituye hoy un peligro no menor que la anterior. El problema de fondo consiste en reducir toda la racionalidad a lo que nos puede decir la ciencia sobre la realidad. Erigir a la ciencia en un conocimiento total, en toda la verdad, conduce finalmente a instalar al hombre en la irracionalidad y a convertir a la misma ciencia en un enemigo para el hombre. La historia se ha encargado de demostrarlo en el siglo pasado. Entonces también queda definitivamente desconectada del conocimiento que proviene de la religión revelada y, consiguientemente, ciencia y fe, o son enemigos, o se firma una amistad que se traduce en la simplicidad de admitir que nada tienen que ver la una con la otra.

Autores como Mariano Artigas ponen de manifiesto cómo la razón en su más amplio sentido, la filosofía, es puente entre la ciencia y la fe. Ninguna de las tres instancias es reducible a las otras dos, ni puede desarrollarse 
de una manera independiente de las demás. La ciencia puede ser camino hacia Dios y la fe revelada. Recientemente lo han testimoniado personajes como Antony Flew o Francis Collins. En ambos casos el punto de partida de sus respectivas conversiones del ateismo o de la indiferencia ha sido precisamente la biología actual. La ciencia, en definitiva, es ejercicio de la razón.

Pero la razón, en particular la filosofía, merece su nombre, y es razonable, cuando mantiene su apertura hacia lo verdadero de una manera desinteresada e irrestricta, no porque lo verdadero sea útil, sino porque es verdadero. Debe reconocer la verdad de otras instancias, en particular la instancia de la fe, debe respetar el misterio presentado por la fe cuando sus propuestas trascienden el alcance de la razón, sin desistir en su intento de entenderlas cada vez mejor. Desistir en el propósito de entender cada vez mejor la verdad del mundo, del hombre y de Dios constituiría la muerte de la racionalidad. Y su muerte dejaría a la razón en manos de la ideología de moda o del poder dominante, o de un pensamiento cientificista o fundamentalista. Sería la renuncia a lo que más propiamente nos pertenece.

La razón y la fe no sólo no son enemigas sino que se han beneficiado mutuamente. Sus relaciones no obstante no han sido siempre fáciles de entender, ni pueden reducirse a un esquema tan simple como el de amistad o enfrentamiento. En lo que sigue voy a tratar de explicitar algunas de las ideas implícitas en lo expuesto. Abordaré, en primer lugar, y muy sucintamente, la pretendida oposición de la Iglesia a las teorías evolutivas. En esta parte el enfoque será principalmente histórico. A continuación expondré, también muy brevemente, la doctrina de la creación que se ha ido fraguando en la interacción de razón y revelación cristiana, divisando sus interacciones con las tesis evolucionistas. Esta doctrina de la creación se distingue netamente de la conocida como "creacionismo", que es abiertamente antagónica con la teoría de la evolución, y que es sostenida principalmente en el ámbito protestante de los Estados Unidos. El creacionismo no será abordado en este trabajo ${ }^{1}$.

1 En (Collado 2009a) se puede leer un resumen de las principales tesis creacionistas. 


\section{Evolución y cristianismo}

La publicación del Origen de las Especies en el año 1859 supuso una auténtica revolución en la manera de entender la biología y la historia de la vida en nuestro planeta. Muchos han considerado que este libro hizo posible dar respuesta a los fenómenos observados en el mundo de los seres vivos desde las ciencias naturales (Ayala 2007).

En el momento en el que se publica el libro de Darwin, las ideas transformistas ya llevaban circulando al menos cincuenta años. Lo que para muchos aportaron Darwin y Wallace fue un mecanismo que permitía dar una explicación plausible y sencilla del aumento de la complejidad en el ámbito de los seres vivos sin necesidad de recurrir a explicaciones de carácter teleológico. Dichas explicaciones eran la base para los argumentos entonces más difundidos de la existencia de Dios. El libro de Darwin parecía hacer innecesario el argumento de la finalidad esgrimido por la apologética de la época y, consiguientemente, Dios era desplazado por la ciencia también en este ámbito. Esta aportación creó una notable división en el mundo cultural de entonces. Por una parte estaban aquellos que veían en la teoría Darwinista una justificación científica para defender el materialismo y, por otra, los que encontraban en dicha teoría una propuesta insuficiente desde el punto de vista científico, o también, desde el filosófico. No pocos vieron en la propuesta de Darwin una seria amenaza contra una comprensión de la realidad concorde con la fe cristiana.

La polémica fue el signo que marcó, desde su inicio, la publicación del Origen de las Especies. Sus ideas plantearon problemas, como ocurrió en el “Caso Galileo", en dos niveles distintos. Por una parte Darwin se enfrentaba con la cosmovisión entonces imperante en el ámbito filosófico. En dicha cosmovisión desempeñaba un papel importante la finalidad. La mecánica de Newton había conseguido despojar de finalidad al mundo físico y, por tanto, la teleología había quedado recluida en el mundo de los seres vivos. El "argumento del diseño" expuesto por Paley a principios del siglo XIX era el paradigma de la cosmovisión teleológica imperante en este momento. Este argumento, que ya no era equivalente al argumento de la finalidad de 
Santo Tomás, parecía quedar sin fundamento como consecuencia de las tesis darwinistas. Por otra parte, las propuestas de Darwin parecían entrar en contradicción con lo que relataban las Sagradas Escrituras. Si a estos dos problemas añadimos el uso ideológico que algunos hicieron del darwinismo para defender el materialismo y el ateísmo y, también, las dificultades de carácter estrictamente científico que pronto surgieron contra lo esencial del darwinismo (pequeñas variaciones más selección natural como causa principal de la evolución) se comprende que, a pesar de su éxito inicial, el darwinismo pasara por momentos de declive y que muchos intelectuales y, en concreto, la mayoría de los teólogos cristianos fueran contrarios al darwinismo y lo consideraran como una teoría difícilmente conciliable con la doctrina cristiana. En cualquier caso el darwinismo revolucionó el ambiente científico, cultural y filosófico de finales del siglo XIX y no dejó a nadie indiferente.

A pesar de la oposición que los teólogos y muchos filósofos ejercieron inicialmente contra la nueva doctrina, sin embargo, la Iglesia Católica como tal, puede decirse que hizo muy pocas declaraciones magisteriales, y muy medidas, en relación con las teorías evolutivas. No cabe duda de que dichas teorías son relevantes para los contenidos de la Fe. De hecho se produjeron denuncias ante las autoridades eclesiásticas de libros que defendían el darwinismo o su compatibilidad con la Fe. Pero también parece claro que la sombra del "Caso Galileo" se ha proyectado sobre el modo en el que el Magisterio de la Iglesia ha abordado los problemas relacionados con el darwinismo (Artigas, Glick and Martínez 2010).

\section{Magisterio y exégesis}

En relación con el darwinismo se puede decir que ha habido dos tipos de intervenciones magisteriales. Unas se refieren de manera directa y explícita al darwinismo. Las otras, sin referirse directamente a esta doctrina, sin embargo, han condicionado las discusiones de tipo teológico que se han mantenido y también, de alguna manera, han preparado las intervenciones explícitas.

Las intervenciones indirectas hacen referencia, fundamentalmente, al modo en que se deben leer las Sagradas Escrituras. Las declaraciones del 
Magisterio en este sentido han servido para que, especialmente en los inicios del siglo XX, la tendencia de la teología católica se distanciara cada vez más de las posiciones mantenidas por los protestantes en Estados Unidos. Estas últimas han sido, en general y a pesar de su falta de unidad, abiertamente beligerantes: dieron lugar en la primera mitad del siglo XX al Fundamentalismo y, en la segunda mitad, al llamado Creacionismo Científico. En cambio, en la teología católica, aunque no han faltado fricciones, hubo una progresiva aceptación de las teorías evolutivas a lo largo del siglo XX.

Es importante tener en cuenta cuando se consultan las fuentes magisteriales que, en relación con la Evolución, se ha ido precisando paulatinamente la terminología. Ahora se distingue, por ejemplo, teorías evolutivas de doctrinas evolucionistas, o evolución de evolucionismo. Las primeras son teorías de carácter puramente científico mientras que en las segundas se incluyen doctrinas de carácter filosófico o, incluso, ideológico. Hay documentos magisteriales en los que haciéndose referencia a las teorías científicas se emplean palabras como "evolucionismo". Esto es lo que ocurre, por ejemplo, en la "Humani Generis".

Tanto las intervenciones de carácter explícito como las de carácter indirecto han sido retomadas e interpretadas nuevamente por el magisterio de Juan Pablo II que ha prestado una gran atención a la relación de la fe con la razón y, en particular también, de las ciencias con la fe. Las implicaciones filosóficas y teológicas de las teorías de la evolución también han sido objeto de atención en el pontificado de Benedicto XVI, que ya se había ocupado de ellas antes de ser papa.

Dos de las intervenciones del magisterio más importantes en relación con la interpretación de la Sagrada Escritura son la encíclica "Providentissimus Deus” de León XIII, publicada en el año 1893, y la encíclica “Divino Afflante Spiritu” de Pio XII, publicada en 1943. Aunque en contextos distintos, ambas establecen los criterios aplicables en la interpretación católica de la Biblia y abordan los problemas que surgen en el trabajo exegético desde dos contextos, en cierto sentido, opuestos. La primera insistió en el carácter inspirado de los textos sagrados cuando ese carácter parecía verse amenazado desde la exégesis liberal. La segunda animaba a integrar las 
verdaderas aportaciones de la crítica literaria y a tomar en consideración los distintos géneros literarios con el fin de llegar a iluminar el verdadero sentido de dichos textos. Una intervención especialmente esclarecedora de Juan Pablo II (1993) que glosa ambas encíclicas, en su unidad y especificidad, fue el discurso pronunciado el 23 de abril de 1993 con motivo del centenario de la primera encíclica y el cincuentenario de la segunda:

En primer lugar, se nota una importante diferencia entre estos dos documentos. Se trata de la parte polémica -o, más precisamente, apologética- de las dos encíclicas. En efecto, ambas manifiestan la preocupación de responder a los ataques contra la interpretación católica de la Biblia, pero estos ataques no iban dirigidos en la misma dirección. La "Providentissimus Deus", por una parte, quiere sobre todo proteger la interpretación católica de la Biblia de los ataques de la ciencia racionalista; por otra parte, la "Divino afflante Spiritu" se preocupa más bien de defender la interpretación católica de los ataques que se oponen a la utilización de la ciencia por parte de los exégetas y que quieren imponer una interpretación no científica, denominada "espiritual”, de la Sagrada Escritura (n. 3). [...] Constatamos que, a pesar de la gran diversidad de las dificultades por afrontar, las dos encíclicas están unidas perfectamente en un nivel más profundo. Ambas refutan, tanto la una como la otra, la ruptura entre lo humano y lo divino, entre la investigación científica y la mirada de la fe, entre el sentido literal y el sentido espiritual. Ambas se muestran en este punto plenamente en armonía con el misterio de la encarnación (n. 5).

El espíritu con el que la Iglesia ha animado a hacer la exégesis de los textos sagrados es expresado por Juan Pablo II en el mismo texto con estas palabras:

[Se trata de] comprender el sentido de los textos con toda la exactitud y precisión posible y, por tanto, en su contexto histórico y cultural. Una falsa idea de Dios y de la Encarnación empuja a un cierto número de cristianos a seguir una orientación contraria. Estos tienen la tendencia a creer que, siendo Dios el Ser absoluto, cada una de sus palabras tienen un valor absoluto, independiente de todos lo condicionamientos del lenguaje humano. [...] Cuando [Dios] se expresa en un lenguaje humano, no da a cada expresión un valor uniforme, sino que utiliza los posibles matices con extrema flexibilidad, y acepta también sus limitaciones (n. 8). 
Juan Pablo II también ha hecho intervenciones que adaptan los principios de los documentos anteriores a la interpretación de los pasajes bíblicos que guardan relación más estrecha con los nuevos conocimientos científicos. En un discurso pronunciado a la Academia Pontificia de las Ciencias el 3 de octubre de 1981 decía lo siguiente:

La Biblia nos habla del origen del universo y de su constitución, no para proporcionarnos un tratado científico, sino para precisar las relaciones del hombre con Dios y con el universo. La Sagrada Escritura quiere declarar simplemente que el mundo ha sido creado por Dios, y para enseñar esta verdad se expresa con los términos de la cosmología usual en la época del redactor. El libro sagrado quiere además comunicar a los hombres que el mundo no ha sido creado como sede de los dioses, tal como lo enseñaban otras cosmogonías y cosmologías, sino que ha sido creado al servicio del hombre y para la gloria de Dios. Cualquier otra enseñanza sobre el origen y la constitución del universo es ajena a las intenciones de la Biblia, que no pretende enseñar cómo ha sido hecho el cielo sino cómo se va al cielo. Cualquier hipótesis científica sobre el origen del mundo, como la de un átomo primitivo de donde se derivaría el conjunto del universo físico, deja abierto el problema que concierne al comienzo del universo. La ciencia no puede resolver por sí misma semejante cuestión: es preciso aquel saber humano que se eleva por encima de la física y de la astrofísica y que se llama metafísica; es preciso, sobre todo, el saber que viene de la revelación de Dios.

Las intervenciones de ámbito universal del Magisterio en relación con las teorías de la evolución, que han sido pocas, han mantenido la coherencia, en lo que a la compatibilidad con la Escritura se refiere, con estos principios.

\section{Intervenciones sobre el darwinismo en la segunda mitad del siglo XIX}

Según lo dicho anteriormente, la atmósfera que rodeó el encuentro entre el darwinismo y la teología católica refleja la tensión que existió en la segunda mitad del siglo XIX entre ciencia y cristianismo. La percepción de muchos era que la teología se veía amenazada por la ciencia. Pero esta percepción era consecuencia de doctrinas e ideologías que se presentaban 
como apoyadas por la ciencia. En el último cuarto del siglo XIX se publican, por ejemplo, libros en los que se defiende la tesis del conflicto permanente entre ciencia y teología. En estos años hubo teólogos que sostenían que pertenecía a la fe la creación divina e inmediata del cuerpo.

El Vaticano, coherentemente con los principios antes señalados, no consideró en este momento a la evolución una doctrina teológica sobre la que tuviera que pronunciarse. La congregación del Santo Oficio es la competente para condenar doctrinas contrarias a la Fe. Pero, de hecho, no hay ninguna intervención de la congregación del Santo Oficio sobre la evolución. Sí hay una intervención de carácter magisterial en relación directa con la evolución en estos años. Se trata del Concilio de Colonia de 1860. En la primera parte de sus decretos, título IV, capítulo XIV, se lee:

Los primeros padres fueron creados [conditi] inmediatamente por Dios. Por tanto, declaramos que es completamente contraria a la Sagrada Escritura y a la fe la opinión de aquellos que no se avergüenzan de afirmar que el hombre, por lo que se refiere al cuerpo, se originó por un cambio espontáneo [spontanea immutatione] de la naturaleza más imperfecta en la más perfecta y, de modo continuo, finalmente humana.

Ciertamente se trata de una condena explicita del origen evolutivo del hombre, pero con matices. No se condenaba el origen evolutivo sin más, sino solamente a quienes afirmaban que ese proceso evolutivo había tenido lugar espontáneamente, es decir, sin el concurso de la acción divina. Se discutía en este caso sólo el origen del cuerpo y no el alma, para la que, por supuesto, se suponía la exigencia de una acción especial divina. Hay que señalar, además, que dicho concilio no tenía autoridad dogmática y que tampoco contó con el reconocimiento de Roma. Lo que sí refleja bien esta reunión es el clima teológico en el que la Iglesia recibe al darwinismo. Pero aunque dicho clima fuera contrario e, inicialmente, los manuales de teología criticaron las teorías evolutivas, sus autores no pudieron dar argumentos de autoridad en el ámbito católico. Entre 1877 y 1900 los manuales, en sus ataques a la evolución, sí hacen referencia a supuestas intervenciones directas de la autoridad de Roma, pero la fuente era siempre La Civiltà Cattolica. Las 
referencias a la autoridad siempre eran indirectas y no citas concretas de intervenciones del magisterio que, de hecho, no se produjeron en ese tiempo.

Lo más destacable de estos años, que se corresponden con el papado de León XIII (1878-1903), son las denuncias hechas ante las autoridades competentes sobre libros de católicos que defendían la compatibilidad de la evolución con la Fe. Esto obligó a intervenir en diversas ocasiones a la Congregación del Índice. Un estudio realizado en 2010 por Mariano Artigas, Thomas Glick y Rafael Martínez se centra en seis autores católicos sobre los que se pronunció esta congregación. Son los casos más representativos del pontificado de León XIII. El resultado del trabajo pone de manifiesto que la teoría de la evolución fue objeto de debate y discusiones dentro de la Congregación del Índice. Aunque hubo diversidad de opiniones, y algunas de ellas abiertamente conciliantes, en general prevalecieron las posiciones contrarias a la nueva teoría. Pero esa oposición se llevó siempre con gran prudencia.

De seis casos estudiados, 2 obispos, 2 religiosos, 1 sacerdote y 1 laico, solamente tres provocaron una intervención de la congregación romana. De estos tres solamente uno, el del sacerdote de la diócesis de Florencia llamado Caverni (1837-1900), provocó una condena que fue publicada mediante decreto en 1878. Su libro Nuevos estudios de filosofía. Discursos a un joven estudiante fue incluido en el Índice de libros prohibidos. Este ha sido en realidad el único caso en el que un libro de un católico fue puesto en el índice por sus ideas evolucionistas. En relación con este caso hay que tener en cuenta que la misma congregación habla de una "condena indirecta” del darwinismo. La Congregación del Î́ndice no se podía apoyar en declaraciones anteriores sobre esta doctrina, y no tenía competencias para decir que algo fuera contrario a la fe sino sólo advertir de los peligros que una lectura podía tener para los cristianos. El artífice principal de la condena fue el cardenal consultor Tommaso Maria Zigliara. En su informe dejó escrito lo siguiente:

la teoría de la evolución es absurda desde el punto de vista metafísico, porque se basa en principios falsos, es una hipótesis arbitraria e incluso contradictoria, e incluso es absurda desde el punto de vista de la fisiología (Martínez 2007, 537). 
Esta declaración es un ejemplo de las opiniones de algunos teólogos del momento. Aunque no era la única postura, sin embargo, tuvo una influencia determinante en estas intervenciones de la Congregación.

También provocaron la intervención de la Congregación un libro de Leroy (1828-1905), religioso dominico, y otro de John A. Zahm (1851-1921), sacerdote norteamericano y profesor de Física en Notre Dame. El caso de Leroy fue el más debatido. Llegó a haber cuatro consultores, el primero, por ejemplo, fue claramente favorable en su dictamen en el que citaba explícitamente a la Providentissimus Deus publicada sólo unos meses antes. El cuarto consultor fue, en cambio, mucho más desfavorable y llevó a la congregación a invitar al autor a retractarse. No se llegó a publicar ninguna condena y el libro no fue por tanto incluido nunca en el Î́ndice. El valor de la condena, al no publicarse, quedó sujeto a diversas interpretaciones. El caso de Zahm tuvo más notoriedad por ser, cuando fue denunciado, postulador general de la orden "Congregación de la Santa Cruz" y por su vinculación con algunos exponentes del "Americanismo". El consultor encargado fue el mismo que intervino en contra de Leroy. En este caso también consiguió una condena del libro de Zahm y que se le instara a hacer una retractación. El consultor, Enrico Buonpensiere, incluso pretendió, y no lo consiguió, que la Congregación condenara la doctrina contraria a que el hombre fue creado inmediata y directamente del limo de la tierra. Al final ni la condena se llegó a hacer pública, ni Zahm tuvo que retractarse. Por tanto, no hubo tampoco ningún documento público por parte de las autoridades romanas a favor o en contra del evolucionismo por este caso.

De este período, por tanto, se puede decir de manera general lo siguiente:

1. Que el Congregación del Santo Oficio no intervino en ninguno de los casos.

2. Que, aunque una mayor parte de los teólogos eran contrarios a la Evolución, no hubo una política determinada en relación con esta doctrina por parte de las autoridades vaticanas. Dichas autoridades eran conscientes de que no existía una decisión doctrinal acerca de la Evolución, y según parece no tenían un excesivo interés en provocarla.

3. Que las intervenciones de la Congregación del Índice se produjeron como respuesta a denuncias concretas interpuestas a dicha congregación y, por 
tanto, la iniciativa no partió de las autoridades romanas. Cuando algunos autores defendieron la compatibilidad de la evolución con la doctrina católica, las autoridades prefirieron no condenarlos con un acto público, sino más bien persuadirlos de que se retractaran de sus ideas, incluso con una simple carta publicada en un periódico.

\section{Intervenciones del Magisterio sobre el darwinismo en el siglo XX}

En el ámbito católico, a diferencia de lo que ocurrió en el protestante en los Estados Unidos, se fue aceptando paulatinamente la compatibilidad de las tesis evolutivas con la doctrina revelada. En el comienzo de los años treinta un autor como Ernst Messenger defendía esa compatibilidad en el ámbito académico sin apenas oposición. En los años 40 este tipo de estudios eran cada vez más frecuentes. Por fin se produjo la primera declaración explícita en un documento magisterial en la encíclica Humani Generis de Pío XII, publicada el 12 de agosto de 1950. Esta declaración ha sido un punto de referencia constante para documentos posteriores.

En el ámbito teológico la situación actual dista notablemente de la que se respiraba en los comienzos del Darwinismo e, incluso, de la que dominaba en los comienzos del siglo XX. La completa consonancia entre lo expresado por el magisterio y el clima teológico actual se puede constatar en documentos como Comunión y servicio. La persona humana creada a imagen de Dios del 23 VII 2004, elaborado por la "Comisión Teológica Internacional". Este documento sintetiza y expone de una manera unitaria y armónica, en sus números $62-70$, los conocimientos que sobre los orígenes han proporcionado las ciencias naturales y las declaraciones de carácter magisterial pronunciadas a lo largo del siglo XX.

\section{Humani Generis}

El papa Pio XII manifiesta en esta encíclica su preocupación por las doctrinas erróneas que de una manera solapada o abierta se estaban difundiendo con daño para las almas y la autoridad de la Iglesia. Denuncia a los que defienden que los conceptos teológicos han de ser sustituidos según los 
sistemas filosóficos que en cada momento den soporte a las explicaciones del dogma. Llama a esto relativismo dogmático. Afirma que es imprudencia querer sustituir lo que tanto trabajo ha costado formular y aquilatar por nuevas nociones de moda que se muestran sumamente efímeras. Hace una defensa en este contexto de la teología de Santo Tomás.

La encíclica alerta sobre el espíritu de novedad que se va imponiendo en muchos hijos de la Iglesia y el daño que esto causa, y se ve en la obligación de recordar el poder de la razón cuando está alimentada por una sana filosofía, la filosofía empleada por el Magisterio, confirmada y aceptada comúnmente por la Iglesia.

Las primeras afirmaciones relacionadas con la Evolución, que se hacen ya en la introducción del texto, se refieren propiamente a la ideología que nace, en parte, de las teorías evolutivas y que propiamente habría que denominar Evolucionismo:

Dando una mirada al mundo moderno, que se halla fuera del redil de Cristo, fácilmente se descubren las principales direcciones que siguen los doctos. Algunos admiten de hecho, sin discreción y sin prudencia, el sistema evolucionista, aunque ni en el mismo campo de las ciencias naturales ha sido probado como indiscutible, y pretenden que hay que extenderlo al origen de todas las cosas, y con temeridad sostienen la hipótesis monista y panteísta de un mundo sujeto a perpetua evolución. Hipótesis, de que se valen bien los comunistas para defender y propagar su materialismo dialéctico y arrancar de las almas toda idea de Dios (n. 3).

Se lamenta más adelante de que algunos se hayan apartado de los principios y normas hermenéuticas establecidas por las encíclicas Providentissimus y Divino afflante Spiritu. Delata que el efecto venenoso de esta actitud se ha notado en casi todos los tratados de teología.

El último apartado lleva por titulo Las ciencias. Es aquí, en el n. 29, donde se recoge el texto clave al que antes hemos hecho referencia:

El Magisterio de la Iglesia no prohíbe el que - según el estado actual de las ciencias y la teología - en las investigaciones y disputas, entre los hombres más competentes de entrambos campos, sea objeto de estudio la doctrina del 
evolucionismo, en cuanto busca el origen del cuerpo humano en una materia viva preexistente - pero la fe católica manda defender que las almas son creadas inmediatamente por Dios-. Mas todo ello ha de hacerse de manera que las razones de una y otra opinión -es decir la defensora y la contraria al evolucionismo - sean examinadas y juzgadas seria, moderada y templadamente; y con tal que todos se muestren dispuestos a someterse al juicio de la Iglesia, a quien Cristo confirió el encargo de interpretar auténticamente las Sagradas Escrituras y defender los dogmas de la fe. Pero algunos traspasan esta libertad de discusión, obrando como si el origen del cuerpo humano de una materia viva preexistente fuese ya absolutamente cierto y demostrado por los datos e indicios hasta el presente hallados y por los raciocinios en ellos fundados; y ello, como si nada hubiese en las fuentes de la revelación que exija la máxima moderación y cautela en esta materia.

Queda claro por el contexto que aquí el término evolucionismo, como antes mencionamos, se refiere a la teoría científica de la evolución y no a la ideología evolucionista mencionada al principio del documento.

\section{Magisterio de Juan Pablo II}

Juan Pablo II se refirió en numerosas ocasiones a la relación entre ciencia y fe. Alertó sobre el peligro del cientificismo como una nueva forma de positivismo que relega el saber teológico y filosófico al ámbito de la mera imaginación (n. 88 de Fides et ratio) y, al mismo tiempo, reconoció los beneficios recibidos por la Iglesia de la ciencia e impulsó diversas iniciativas en las que buscaba poner de manifiesto la compatibilidad entre ambas o resolver viejas disputas, como fue el conocido "Caso Galileo". En particular hizo diversas declaraciones relacionadas con las doctrinas evolucionistas.

En un texto de su catequesis del 16 de abril de 1986 afirmaba:

Por tanto se puede decir que, desde el punto de vista de la doctrina de la fe, no se ve dificultad en explicar el origen del hombre, en cuanto al cuerpo, mediante la hipótesis del evolucionismo. Sin embargo, hay que añadir que la hipótesis propone sólo una probabilidad, no una certeza científica. La doctrina de la fe, en cambio, afirma invariablemente que el alma espiritual del hombre ha sido creada directamente por Dios. Es decir, según la hipótesis a la que hemos aludi- 
do, es posible que el cuerpo humano, siguiendo el orden impreso por el Creador en las energías de la vida, haya sido gradualmente preparado en las formas de seres vivientes anteriores. Pero el alma humana, de la que depende en definitiva la humanidad del hombre, por ser espiritual, no puede serlo de la materia.

Este texto mantiene una sintonía completa, incluso en la estructura, con el texto de la Humani Generis: no hay problema en aceptar las teorías evolutivas que se refieren al origen del hombre en cuanto al cuerpo, se debe ser prudente al hacer estas afirmaciones puesto que no se trata todavía de una absoluta certeza científica y, esto es lo más importante, el alma humana exige una intervención directa de Dios. Se da por supuesto que la evolución en el ámbito no humano no presenta ningún problema para la Fe.

Juan Pablo II dio un paso más cuando afirmó en un mensaje, frecuentemente citado, a los miembros de la Academia Pontificia de las Ciencias del 22 de octubre de 1996 lo siguiente:

Teniendo en cuenta el estado de las investigaciones científicas de esa época y también las exigencias propias de la teología, la encíclica Humani generis consideraba la doctrina del "evolucionismo" como una hipótesis seria, digna de una investigación y de una reflexión profundas, al igual que la hipótesis opuesta. Pío XII añadía dos condiciones de orden metodológico: que no se adoptara esta opinión como si se tratara de una doctrina cierta y demostrada, y como si se pudiera hacer totalmente abstracción de la Revelación a propósito de las cuestiones que esa doctrina plantea. [...] Hoy, casi medio siglo después de la publicación de la encíclica, nuevos conocimientos llevan a pensar que la teoría de la evolución es más que una hipótesis. En efecto, es notable que esta teoría se haya impuesto paulatinamente al espíritu de los investigadores, a causa de una serie de descubrimientos hechos en diversas disciplinas del saber. La convergencia, de ningún modo buscada o provocada, de los resultados de trabajos realizados independientemente unos de otros, constituye de suyo un argumento significativo en favor de esta teoría (n. 4).

Lo que añade este texto a la doctrina anterior es el reconocimiento de que la teoría científica de la evolución se ha impuesto de una manera clara en el ámbito científico, alcanzando el estatuto de una verdadera teoría cien- 
tífica. En el contenido del mensaje hace otra serie de interesantes consideraciones de carácter epistemológico sobre el alcance y significación de una teoría científica y su estrecha relación con la filosofía. Afirma que se puede hablar de teorías de la evolución más que de una única teoría de la evolución. Esto es así desde el punto de vista puramente científico pero también como consecuencia de la diversidad de contextos filosóficos en las que estas explicaciones se encuadran. Este hecho lleva a que se puedan hacer lecturas materialistas y espiritualistas de la evolución. Afirma el pontífice, en continuidad con la doctrina formulada anteriormente, la existencia de un "salto ontológico" cuando nos referimos al hombre. Deja claro que defender ese salto ontológico al hablar del origen del hombre no entra en contradicción con las investigaciones de las ciencias:

La consideración del método utilizado en los diversos campos del saber permite poner de acuerdo dos puntos de vista, que parecerían irreconciliables. Las ciencias de la observación describen y miden cada vez con mayor precisión las múltiples manifestaciones de la vida y las inscriben en la línea del tiempo. El momento del paso a lo espiritual no es objeto de una observación de este tipo que, sin embargo, a nivel experimental, puede descubrir una serie de signos muy valiosos del carácter específico del ser humano. Pero la experiencia del saber metafísico, la de la conciencia de sí y de su índole reflexiva, la de la conciencia moral, la de la libertad o, incluso, la experiencia estética y religiosa competen al análisis y de la reflexión filosóficas, mientras que la teología deduce el sentido último según los designios del Creador (n. 6).

\section{Benedicto XVI}

El interés de Benedicto XVI por estos temas, mucho antes de ser papa, ha quedado bien patente en diversos escritos. Uno de los más importantes fue el libro publicado en 1985 con el título "Creación y pecado”, en el que se incluyen una serie de homilías sobre los primeros capítulos del Génesis. Siendo ya papa quiso dedicar un encuentro, como los que solía mantener con sus alumnos universitarios durante su etapa académica, al tema de la relación entre Creación y Evolución. También ha hecho múltiples de- 
claraciones sobre este tema en diferentes discursos. Las afirmaciones de Benedicto XVI, en continuidad con Juan Pablo II y el magisterio anterior, destacan la no existencia de contradicción entre la visión bíblica y nuestros conocimientos científicos. Más que contradicción hay una complementariedad que supone un enriquecimiento mutuo.

Ratzinger también abordó nociones filosóficas y teológicas que pueden resultar más difíciles de comprender y que son claves en este debate. Una que nos parece especialmente importante es la de "creación inmediata del alma humana por Dios”. Un libro recientemente publicado con algunas antiguas intervenciones suyas contiene un capítulo en el que se aborda esta difícil cuestión (Ratzinger 2011, 117-130). No podemos abordar aquí el contenido de este texto.

En las intervenciones que tuvo Benedicto XVI durante su pontificado puso un cuidado especial en salir al paso de las interpretaciones materialistas que han sido difundidas abiertamente por algunos autores. Una expresión de este interés fueron las palabras pronunciadas en la homilía del comienzo de su pontificado: "No somos el producto casual y sin sentido de la evolución. Cada uno de nosotros es el fruto de un pensamiento de Dios. Cada uno de nosotros es querido, cada uno es amado, cada uno es necesario" (24 de abril de 2005).

\section{Creación y evolución}

El mecanismo darwiniano pasó por distintas fases en cuanto a su grado de aceptación por parte la comunidad científica en la segunda mitad del siglo XIX. El mismo Darwin llegó a considerar que no era el único mecanismo causante de la evolución. A lo largo del siglo XX se consiguió hacer una síntesis de las propuestas darwinistas con los principios de la genética descubiertos por Mendel también en la segunda mitad del siglo XIX. A mediados del siglo XX la “Teoría Sintética de la Evolución”, que unía las aportaciones de Darwin y Mendel, dominaba completamente el ámbito académico y científico. Los nuevos hallazgos de la genética y la bioquímica han reforzado las líneas generales de la teoría sintética aunque también se 
han abierto nuevos interrogantes y desafíos que, no obstante, no parecen amenazar lo sustancial de la actual teoría de la evolución.

Nadie discute en el ámbito científico lo que se denomina "el hecho" de la evolución, es decir, que todas las especies animales, incluido el hombre, no han existido siempre como las observamos sino que proceden de otras anteriores por evolución. Hoy los biólogos están en condiciones, y la genética moderna está ayudando a conseguirlo, de confeccionar un árbol de la vida donde poder colocar desde los primeros seres vivos existentes hace aproximadamente tres mil quinientos millones de años, hasta las especies existentes en nuestros días. Estas últimas, lógicamente, estarían en las ramas extremas del árbol. En la actualidad se sigue debatiendo sobre los mecanismos de la evolución, sobre el papel de la selección natural, o la necesidad de completar la teoría sintética con nuevos elementos que expliquen algunas de las incógnitas actuales. Pero el cuadro general evolutivo es aceptado por prácticamente toda la comunidad científica.

\section{Posiciones en relación con la compatibilidad de ciencia y fe}

En cuanto a la relación de las teorías evolutivas científicamente admitidas con la fe cristiana se puede decir que se han dado cuatro posiciones básicas (Carlson 2000):

1. Incompatibilidad entre la fe revelada y las afirmaciones de la ciencia.

2. Compatibilidad entre fe y ciencia ya que ambas pertenecen a esferas del conocimiento que son completamente independientes.

3. Los datos de la ciencia actual no sólo son incompatibles con la fe sino que la refuerzan y ofrecen elementos para una confirmación científica de tesis propias de la fe.

4. Ciencia y religión se mueven en ámbitos metodológicos distintos y autónomos pero existe armonía entre ambas.

Estas posiciones son la consecuencia del modo de ver la relación de Dios con el mundo y con el hombre. La primera posición -incompatibilidad- depende de una interpretación literalista de la Sagrada Escritura, es decir, surge como resultado de considerar que la Biblia ofrece datos de 
carácter científico sobre el mundo y la aparición del hombre. Este tipo de lectura es la que ha llevado a muchos protestantes norteamericanos al creacionismo fundamentalista, al comienzo del siglo XX, y al llamado “Creacionismo Científico" a partir de los años 70. Para ellos la fe y el marco presentado actualmente por la ciencia son irreconciliables. Esta posición ha sido también defendida desde el lado de la ciencia por algunos que, ya desde la publicación del "Origen de las especies”, vieron en sus tesis una alternativa a las explicaciones basadas en la noción de creación. En este caso, en el que se defiende la incompatibilidad, unos niegan la evolución, mientras que los otros niegan la acción creadora de Dios, o lo que es equivalente, a Dios mismo.

La segunda opción, compatibilidad desde la completa independencia, ha sido también defendida tanto por creyentes como por científicos no creyentes. Esta es, por ejemplo, la posición del famoso científico agnóstico Stephen Jay Gould, conocida como “Non-overlapping magisteria” (NOMA). También el conocido biólogo Francisco Ayala parece defender una posición semejante. Aunque esta tesis puede parecer correcta porque no ve incompatibilidad entre ciencia y religión, en realidad aísla nuestra experiencia del mundo, a la que hoy en día contribuyen de una manera decisiva las ciencias, de nuestro conocimiento de Dios. Este enfoque separa completamente a la creación, que queda recluida en el ámbito de la fe subjetiva, de la evolución. En realidad esta posición es equivalente a la deísta, que pone a Dios en el pasado y deja el presente en manos de los procesos naturales y fuera del alcance de la acción divina. El problema es que si Dios no es necesario para explicar el presente, ponerlo en el pasado acaba siendo una opción basada en preferencias subjetivas o de fe, pero no sustentada por argumentos verdaderamente racionales.

La tercera opción es la que, al menos indirectamente, defienden los partidarios del movimiento conocido como "Diseño Inteligente". Para ellos los recientes descubrimientos de la ciencia, en particular de la bioquímica, ofrecen evidencia empírica de la existencia de un diseño inteligente. Aunque en general no se pronuncian sobre la naturaleza de esa inteligencia, está claro que apuntan, algunos a veces lo dicen de manera explícita, 
a que dicha inteligencia es la divina. El problema de esta opción no es que defiendan que los procesos y estructuras de la naturaleza remitan a una inteligencia creadora. El peligro que encierra esta posición es el opuesto al de la anterior, y consiste en ver a Dios implicado categorialmente en la creación, es decir, se concibe a un Dios que interviene directamente en las transformaciones del mundo natural, las mismas transformaciones que son objeto de estudio de las ciencias. Se da aquí un problema de carácter metódico: no distinguir adecuadamente el nivel en el que actúa el Creador del nivel de la acción propia de los agentes creados.

En las posiciones comentadas hasta el momento hay dos problemas fundamentales. El primero tiene que ver con el tipo de lectura que se hace de la Sagrada Escritura. El otro tiene que ver con el tipo de racionalidad imperante en la cultura de la época en la que nacen las teorías evolutivas. En el siglo XVIII y XIX el paradigma de ciencia natural es la mecánica. El éxito de esta física llevó a que en el ámbito filosófico también se impusiera lo que se podría calificar como filosofía mecánica. Una de las consecuencias del dominio de este tipo de racionalidad fue el desprestigio y arrinconamiento de la metafísica. Este fenómeno, que constituye una carencia gnoseológica, hizo que muchos pensadores vieran en el darwinismo una doctrina que, por fin, haría innecesario el recurso a Dios para explicar el mundo. Es decir, se vio la creación y la evolución como alternativas incompatibles.

En realidad, en algunos de los grandes pensadores cristianos de la época patrística, y también medieval, se puede ver no sólo la no existencia de incompatibilidad entre evolución y creación sino que incluso se consideran complementarias. S. Agustín, por ejemplo, habla de las "raciones seminales" con las que busca hacer compatible la doctrina de la creación con el hecho, claro para él, de que la realidad no fue creada tal como nosotros la contemplamos ahora. Lo que vemos procede de formas previas sobre las que han actuado leyes naturales (De genesis ad litteram 9, 17, 32).

Otros padres como S. Atanasio, S. Basilio y S. Gregorio de Nisa hablan también de la creación como un acto divino pero que se despliega en el tiempo. En la época medieval san Buenaventura y santo Tomás mantienen la misma perspectiva. 
El debate provocado por la publicación del "Origen de las especies", cuya raíz ya se ha apuntado, ha llevado, en el ámbito católico, a volver en la filosofía a las inspiraciones de fondo de los pensadores cristianos mencionados, en particular, a una metafísica realista de inspiración Tomista. Se ha podido desarrollar así una teología de la creación en la que las teorías evolutivas no solamente no son incompatibles con la fe sino que están en buena armonía con ella. Dicha teología de la creación sí se enfrenta a doctrinas filosóficas evolucionistas que apoyándose en las teorías evolutivas defienden principios materialistas o ateos.

Veremos ahora las consecuencias más importantes de la doctrina teológica de la creación en los puntos destacados anteriormente como conflictivos: en la interpretación del génesis y en la propia noción de creación.

\section{Evolución y doctrina teológica de la creación}

\section{Evolución y génesis}

En relación con la narración de la creación contenida en los primeros capítulos del Génesis hay que tener en cuenta que su lectura debe hacerse a la luz del conjunto de la revelación y, en último término, a la luz de la plenitud de la revelación contenida en el Nuevo Testamento en el que Jesucristo es la clave de interpretación de toda la Sagrada Escritura.

Por otra parte, el mensaje que se trasmite en la Biblia está orientado principalmente a la relación del hombre con Dios, y secundariamente del hombre con el mundo. El mensaje bíblico, también cuando se expresa en términos cosmológicos, es de carácter teológico y antropológico. Las ciencias ofrecen una perspectiva distinta: se centran en las trasformaciones materiales que ocurren en el mundo físico. Olvidar esta distinción tiene graves consecuencias porque lleva a considerar que la ciencia es la única que tiene autoridad para hablarnos de lo que es el mundo. La importancia de desarrollar una teología de la creación es patente. La fe en un Dios en el que no se comprende su relación real con el mundo lleva, antes o después, a una fe sentimental. Es importante identificar el Dios creador con el Dios de la salvación. 
De acuerdo con los criterios exegéticos establecidos por el magisterio, y lo dicho anteriormente, se podría resumir el mensaje teológico y antropológico contenido en las narraciones yahvista y sacerdotal del Génesis en los siguientes puntos:

- Todo lo que existe depende de un único Dios.

- Lo creado tiene como origen el Logos, su Palabra, y no una especie de emanación (“y dijo Dios”).

- Lo creado es distinto de Dios, expresa un proyecto libre suyo que se despliega en el tiempo con orden y gradualmente, participando este proyecto de la bondad y perfección divina.

- El hombre y la mujer se asemejan a Dios más que ninguna otra criatura y su creación se presenta como un nuevo acto divino rodeado de una especial solemnidad y trascendencia (triple bará).

- Dios se empeña en la creación del hombre con una acción que indica la donación de su propio espíritu. Hombre y mujer están llamados a una especial intimidad con Dios, pero una relación en la que el ser humano es libre y responsable de sus propias acciones.

- La creación no nace en un contexto de lucha o conflicto entre fuerzas contrarias sino como acto de la voluntad creadora de Dios.

- Pertenece a la verdad originaria la creación de hombre y mujer a imagen y semejanza de Dios. El hombre no procede enteramente de ninguna de las realidades creadas previamente, no es el fruto de un proceso necesario sino que Dios actúa de una manera nueva pero sirviéndose de materia preexistente.

- Existencia de una prueba originaria. Caída moral con consecuencias para todo el género humano: en la relación con uno mismo, del hombre con la mujer y del hombre con Dios. Hay como una herida o insuficiencia en el origen mismo de la humanidad.

- En relación con el ser humano se destaca la dependencia especial que éste tiene para con Dios. Dicha relación se expresa como una creación directa del alma humana.

En estos puntos nada hay que se oponga o entre en contradicción con lo que dice la ciencia sobre la evolución. Incluso, teniendo en cuenta los gé- 
neros literarios, se invita a pensar en una "creación evolutiva” y se rechaza una "evolución creativa" en el sentido en el que la defienden las doctrinas de carácter materialista.

\section{Noción de creación}

El dato revelado de que el mundo ha sido creado "ex nihilo" ha impulsado el desarrollo de una auténtica filosofía sobre la creación, es decir, un discurso sobre la creación sustentado sobre principios exclusivamente racionales. Es de fe que la contemplación del mundo natural constituye una vía para remontarnos racionalmente hasta su Creador. La doctrina filosófica y teológica de la creación pone de manifiesto dónde se encuentran los puntos de fricción que han surgido y todavía surgen a la hora de conciliar creación con evolución, y destaca la coherencia, e incluso conveniencia, de la existencia de evolución en la naturaleza.

La noción de creación, en el ámbito metafísico y teológico, no expresa otra cosa sino la peculiar relación de Dios con el mundo físico, y de Dios con el hombre. Su comprensión es difícil porque tendemos a pensar la realidad física en términos productivos y la creación es una relación que escapa a las categorías ordinarias de nuestro pensamiento. Esa dificultad está presente en todos los debates que se mantienen actualmente en torno a la relación entre ciencia y fe. El lenguaje usual, la misma palabra "relación”, puede desorientar y dificultar la comprensión de la peculiaridad del acto creador.

La creación no es producción, no es generación, sino que es un acto más radical que afecta la "totalidad" del ser.

Algunas propiedades que se derivan de este acto peculiar son:

a) El Creador no sufre cambio o modificación alguna por haber creado, no se hace más perfecto o se completa de alguna manera. El ser divino no es afectado por la creación. Dios no se entiende en dependencia o respecto a su criatura, es decir, ésta no modifica el ser de Dios en absoluto.

b) La criatura depende del creador y no de cualquier manera, sino de una manera radical, depende de Dios en su mismo ser, como prin- 
cipio de su existencia. No se trata de dependencia en cuanto a que se es esto o lo otro en sentido predicativo, sino que se trata de dependencia en el ser en el sentido más radical: "acto de ser”. Crear no implica movimiento, sí donación del ser. Al crear ocurre una novedad radical. Pero esa novedad no es respecto de Dios sino respecto de la nada, porque Dios no se ve modificado al crear. La dependencia de la criatura respecto al creador es por tanto real en el sentido más radical de la palabra. El creador, en cambio, no depende de la criatura, por eso se dice, a veces, que su relación con respecto a la criatura no es real sino de razón: hay que entender esto en ese sentido.

La distinción entre el ser de Dios y de la criatura está en la identidad originaria de uno y la inidentidad o composición metafísica del otro. En términos tomistas se trata de la "distinctio realis" en las criaturas. La dependencia de la criatura con respecto a su creador es la que se corresponde con su inidentidad. Algunos neotomistas denominan a esto ser por esencia o ser por participación.

Es más propio decir que la criatura se distingue de la nada a decir que se distingue de Dios. Lo último parece establecer una relación de la criatura con Dios entre iguales, relación que no sería tan radical como la propia del ser creado. Esto no significa que se confunda Dios con su criatura. Precisamente ocurre lo contrario porque Dios no depende en ningún sentido de su criatura y la criatura depende de Dios en el sentido más radical. Esa radicalidad es la que lleva consigo trascendencia. Dios crea sin movimiento y por esto es trascendente a lo intramundano. Es propio de lo creado el movimiento en virtud de su inidentidad original, o su limitación. La dependencia de la criatura respecto al creador trasciende el movimiento propio de lo intramundano.

Se rechaza de esta manera tanto el panteísmo, en el que se confunden Dios, mundo y hombre, como el panenteísmo en el que el mundo es como una emanación de Dios: Dios es más que el mundo pero el mundo forma parte de Dios. Esta comprensión de la creación establece un doble nivel de actividad que hay que situar en planos radicalmente distintos pero en el que una, la acción creadora, es fundamento de la otra, la acción propia 
de las criaturas, que es descrita parcialmente mediante leyes. La filosofía de tradición tomista habla de causalidad primera y segunda. Los ámbitos metódicos en los que se mueven la doctrina filosófica y teológica de la creación (metafísico) y las teorías evolutivas (científico) hacen que no sea posible demostrar directamente la una desde la otra. La relación entre ambas no es inmediata como pretenden algunas de las posiciones descritas anteriormente. Pero sí se pone de manifiesto su compatibilidad e incluso su coherencia y complementariedad. Refiriéndonos al ámbito físico, Dios es el fundamento de un mundo en el que se pueden estudiar con el método científico, y consiguientemente de una manera parcial, las causas de sus transformaciones y evolución. Es muy significativo el siguiente texto de S. Tomás:

"La naturaleza es, precisamente, el plan de un cierto arte (concretamente, el arte divino), impreso en las cosas, por el cual las cosas mismas se mueven hacia un fin determinado: como si el artífice que fabrica una nave pudiera otorgar a los leños que se moviesen por sí mismos para formar la estructura de la nave” (Comentario a la Física de Aristóteles, II, 14, 8.).

Resulta patente que un Dios que crea un mundo capaz de dar lugar por sí mismo a la riqueza y variedad de los seres naturales, y la racionalidad por la que se rigen, es mucho más poderoso que un dios que tuviera que intervenir continuamente para conseguir esos mismos efectos. Esto no significa que Dios crea y abandona el Mundo al imperio de las leyes que El mismo ha establecido, sino que constituye el fundamento del Mundo y de las leyes por las que se rige. Dicho fundamento trasciende el tiempo y, por tanto, no se puede entender propiamente en términos científicos. Pero las ciencias constituyen una gran ayuda para desarrollar una filosofía que profundice más y mejor en el conocimiento de Dios.

\section{Referencias}

Agazzi, Evandro. 1983. “Scienza e fede. Nuove prospettive su un vecchio problema”. XXVIII Rencontre International du S.I.E.S.C (Varese, 1982). Milano: Massimo. Agustín de Hipona. De genesis ad litteram. 
Artigas, Mariano y Daniel Turbón. 2008. Origen del hombre. Ciencia, Filosofía y Religión. Pamplona: Eunsa.

Artigas, Mariano, Thomas F. Glick, and Rafael A. Martínez. 2010. Seis católicos evolucionistas. El Vaticano frente a la Evolución (1877-1902). Madrid: BAC.

Ayala, Francisco J. 2007. Darwin y el diseño inteligente: creacionismo, cristianismo y evolución. Madrid: Alianza.

Carlson, R. F., ed. 2000. Science \& Christianity: Four Views. Illinois: InterVarsity Press.

Collado, Santiago. 2009a. “Panorámica del debate creacionismo-evolucionismo en los últimos cien años en USA”. Anuario de Historia de la Iglesia 18: 41-53.

-. 2009b “Teoría de la Evolución”. In Philosophica: Enciclopedia filosófica on line. http://www.philosophica.info/voces/evolucion/Evolucion.html.

Comisión Teológica Internacional, Comunión y servicio. La persona humana creada a imagen de Dios (23 VII 2004).

Juan Pablo II. 1986. El hombre, imagen de Dios, es un ser espiritual y corporal. Catequesis (16-IV-1986).

-. 1993. Discurso en el centenario de la "Providentissimus Deus" y el cincuentenario de la encíclica "Divino afflante Spiritu” (23-IV-1993).

-. 1996. Discurso a la Pontificia Academia de las Ciencias (22-X-1996).

Martínez, Rafael. 2007. "El Vaticano y la evolución. La recepción del darwinismo en el Archivo del Índice.” Scripta Theologica 39: 529-549.

Morales, José. 1994. El Misterio de la Creación. Pamplona: Eunsa.

Pío XII. 1950. Humani Generis (22-VIII-1950).

Ratzinger, Joseph. 2005. Creación y pecado. Pamplona: Eunsa.

-. 2011. Fe y ciencia: un diálogo necesario. Santander: Sal Terrae.

Pérez, Carlos, and Héctor L. Mancini. 2006. El Origen del Universo. Accessed March 4, 2014. http://www.unav.es/cryf/origenuniverso.html.

Shea, William R., and Mariano Artigas. 2003. Galileo en Roma: crónica de 500 días. Madrid: Encuentro.

Tanzella-Nitti, Giuseppe. 2001. “Creazione.” In Dizionario Interdisciplinare di Scienza e Fede, edited by Giuseppe Tanzella-Nitti and Alberto Strumia. Roma: Città Nuova.

Tomás de Aquino. Comentario a la Física de Aristóteles. 